\title{
PHENYL-CYCLOPENTADIENYL RULE
}

\author{
Jelena Đurđević, Ivan Gutman \\ Faculty of Science, University of Kragujevac, P. O. Box 60, 34000 Kragujevac, Serbia \\ jddjurdjevic@gmail.com,gutman@kg.ac.rs
}

\begin{abstract}
Within a systematic study of cyclic conjugation in the benzo-annelated derivatives of acenaphthylene and fluoranthene, a general regularity was discovered, named phenyl-cyclopentadienyl rule (PCP rule). According to this rule, six-membered rings connected to the five-membered ring by a single carbon-carbon bond increase the magnitude of cyclic conjugation in the five-membered ring. The greater the number of such six-membered rings is, the stronger the cyclic conjugation in the five-membered ring. The PCP rule was initially established by studying the energy effects of individual rings, and was eventually corroborated by a variety of other independent approaches (Wiberg bond orders, carbon-carbon bond lengths calculated by high-level ab initio DFT methods, multicenter delocalization indices, ring currents).
\end{abstract}

Keywords: polycyclic aromatic hydrocarbons; cyclic conjugation; energy effect of cyclic conjugation; acenaphthylene; fluoranthene; DFT; multicenter bond indices; ring currents; NICS

\section{ПРАВИЛО НА ФЕНИЛ-ЦИКЛОПЕНТАДИЕНИЛ}

При системското испитување на цикличната конјугација на бензоанелираните деривати на аценафтилен и флуорантен, беше најдена општата зависност позната како правило на фенилцилопентадиенил, или накусо правило РСР. Според ова правило шесточлените прстени поврзани со петочлени со единична врска јаглерод-јаглерод ја засилуваат големината на конјугацијата во петочлениот прстен. Така, колку што е поголем бројот на шесточлените прстени толку е посилна цикличната конјугација во петочлениот прстен. Првично правилото РСР било установено при испитување на енергетските ефекти во одделните прстени и потврдено со разновидноста на независните пристапи (редот на врските според Виберг, должината на врските јаглерод-јаглерод пресметана со методите DFT, индексите при повеќецентрична делокализација, струите во прстените).

Клучни зборови: полициклични ароматични јаглеводороди; циклична конјугација; енергетски ефект на цикличната конјугација; аценафтилен; флуорантен; DFT; индекси при повеќецентрична делокализација; струи во прстените; NICS

\section{INTRODUCTION}

Polycyclic aromatic hydrocarbons (PAHs) include a large number of organic molecules consisting of fused aromatic rings devoid of heteroatoms or substituents $[1,2]$. This major class of organic molecules may contain rings of different sizes, but usually these rings are six-membered and five-membered. Non-alternant cyclopenta-fused PAHs consisting of at least one five-membered ring are of substantial chemical importance. Compounds from this class are formed during pyrolysis or as products of incomplete combustion of hydrocarbons fuels $[3,4]$. These can be considered as part of fullerenes and nanotubes, and, additionally, 
these are precursors of soot and are present in coal tar. Cyclopenta-fused PAHs are environmental pollutants and some of them are known to be particularly mutagenic [5]. These molecules are also interesting because they exhibit anomalous fluorescence [6].

In view of the above-mentioned, it is remarkable that a systematic examination of the topology-based properties of cyclopenta-fused PAHs was initiated only quite recently [7] and only a few works along these lines have been published so far [8-10]. This is even more surprising if one knows that the molecular-topology based properties of benzenoid hydrocarbons (PAHs in which all rings are six-membered) are being studied over a whole century and belong to the best elaborated parts of theoretical organic chemistry [11-13].

A method often used for examination of the $\pi$-electron properties of PAHs is the calculation of the energy effect of individual rings. This method is based on a combination of chemical graph theory and molecular orbital theory. Its details are outlined in the reviews $[14,15]$ and elsewhere [16-19]. The energy effect $e f=e f(Z)$ of a cycle $Z$ measures the extent of cyclic conjugation in this respective. Let $Z$ be a cycle in a conjugated molecule whose molecular graph is $G$. Then $[14,15]$

$$
e f(Z)=\frac{2}{\pi} \int_{0}^{\infty} \ln \left|\frac{\phi(G, i x)}{\phi(G, i x)+2 \phi(G-Z, i x)}\right| d x
$$

where $\phi(G, x)$ is the characteristic polynomial of $G, G-Z$ is the subgraph obtained by deleting the cycle $Z$ from $G$, and $i=\sqrt{-1}$; for details of chemical graph theory see $[20,21]$. In equation (1) the energy effect is expressed in units of the HMO carbon-carbon resonance integral $\beta$. It should be noted that because $\beta$ is negative valued, positive values of $e f$ indicate thermodynamic stabilization caused by cyclic conjugation in the respective ring. The greater is $e f$, the greater is the intensity of cyclic conjugation.

Based on their chemical and physical properties, acenaphthylene, fluoranthene, and their congeners should have been included among benzenoid hydrocarbons. Yet, because of the presence of a five-membered ring, these polycyclic conjugated species were excluded from the chemical-graph-theoretical considerations pertaining to benzenoid hydrocarbons [11-13]. Systematic theoretical studies of these compounds (especially within chemical graph theory) started only in 2008 [7, 22, 23].

In Figure 1 are depicted acenaphthylene (1) and two of its congeners $(2,3)$, as well as fluoranthene (4) and two of its congeners $(\mathbf{5}, \mathbf{6})$. From these examples one can immediately get an idea of their general structure.

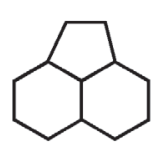

1

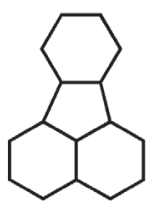

4

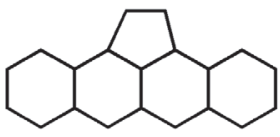

2

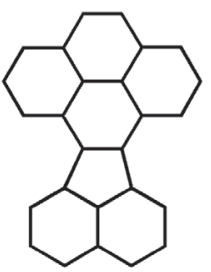

5

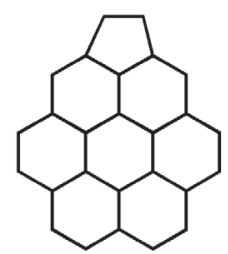

3

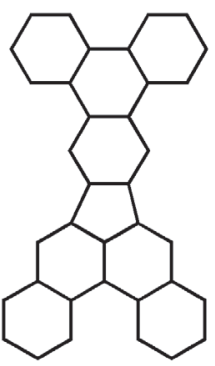

6
Fig. 1. Acenaphthylene (1) and some of its congeners $(\mathbf{2}, \mathbf{3})$, and fluoranthene (4) and some of its congeners $(\mathbf{5}, \mathbf{6})$

Acenaphthylenes and fluoranthenes are structurally very similar to benzenoid hydrocarbons. Acenaphthylene may be viewed as naphthalene to which was added one five-membered ring. Fluoranthene may be viewed as being obtained by joining naphthalene with benzene, so as to form a new five-membered ring. Other polycyclic conjugated species obtained by adding five-membered ring to a benzenoid system or obtained by joining two benzenoid systems so as to form a new five-membered ring will be named acenaphthylenes or fluoranthenes, respectively. By convention, these 
compounds possess exactly one five-membered ring. The general formula of acenaphthylenes and fluoranthenes [7] is depicted in Figure 2.

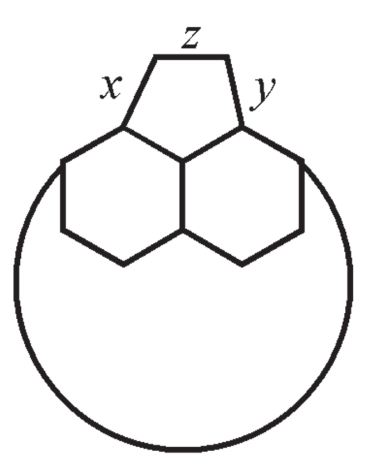

A

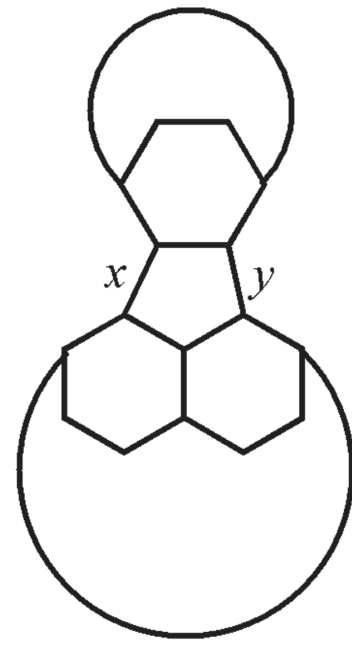

$\mathrm{F}$
Fig. 2. General formulas of acenaphthylenes (A) and fluoranthenes $(\mathrm{F})$. In all their Kekulé structures, the carbon-carbon bonds marked as $x, y$, and $z$ (in acenaphthylenes), and $x$ and $y$ (in fluoranthenes) are localized. Illustrative examples of this localization are given in Figure 3. As usual, here and in the following figures (except Figure 3), double bonds are omitted for the sake of clarity.
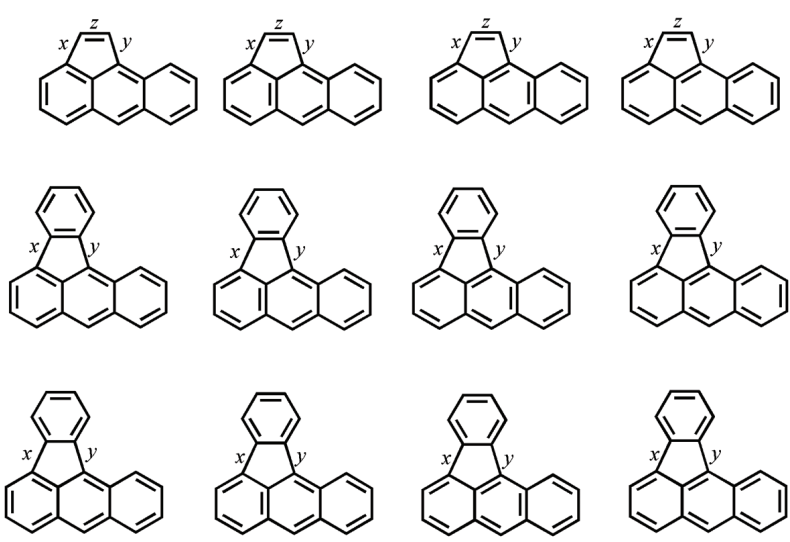

Fig. 3. The four Kekulé structures of aceanthrylene and the eight Kekulé structures of benzo[a]fluoranthene. In all these structures the carbon-carbon bonds marked by $x$ and $y$ are single, and those marked by $z$ double, cf. Figure 2 .
From Figure 2 it is evident that acenaphthylenes and fluoranthenes differ form benzenoids by possessing a single five-membered ring.

\section{CYCLYCIC CONJUGATION IN ACENAPHTHYLENES AND FLUORANTHENES}

As mentioned above, the $\pi$-electron properties of benzenoid systems were extensively studied. On the other hand, acenaphthylenes and fluoranthenes were excluded from these studies because of the presence of the five-membered ring. The fact that the carboncarbon bonds $x, y$ and $z$ in acenaphthylenes and the bonds $x$ and $y$ in fluoranthenes (cf. Figures 2 and 3) are localized in all Kekulé structures $[24,25]$ might be the main reason why these molecules were neglected for so long. Other methods (the "classical" theories [12, 13, 26]) for assessing the intensity of cyclic conjugation based on Kekulé structures, Clar formulas, or conjugated circuits, would predict no cyclic conjugation at all in the five-membered ring of the acenaphthylenes and fluoranthenes. At first glance, calculations based on the ef-method, Eq. (1), point towards the same conclusion. Namely, the ef-values of the five membered rings are one or two orders of magnitude smaller than the ef-values of the other six-membered rings in the same molecule. Yet, the ef-values of the five-membered rings are not zero and are by no means negligible, and exhibit a remarkable dependence on molecular structure. The detailed study of this dependence resulted in our PCP rule, which is the topic of the present review.

In order to gain a better understanding of the $\pi$-electron properties of acenaphthylenes and fluoranthenes, a systematic study of their cyclic conjugation has been undertaken [2729]. Initially, we used only the ef-method, based on Eq. (1). By examining the energy effects of cyclic conjugation in the five-membered ring of various acenaphthylene and fluoranthene congeners an unusual effect could be observed. It was found that the magnitude of the cyclic con- 
jugation in the five-membered ring in a peculiar manner depends on how six-membered rings are connected with the five-membered ring. These regularities are outlined in due detail in the following sections.

\section{THE PHENYL- CYCLOPENTADIENYL RULE}

By examining the energy effects of cyclic conjugation in the five-membered ring of various acenaphthylenes, a peculiar effect could be provided. It was observed that the energy effects exhibit a great variability and in some cases significantly exceed the value for the energy effect of the five-membered ring of the parent acenaphthylene. This is illustrated in Figure 4.

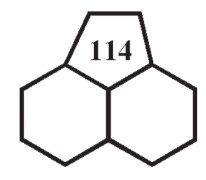

$A_{1}$

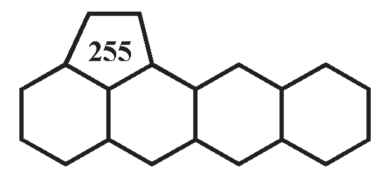

$A_{3}$

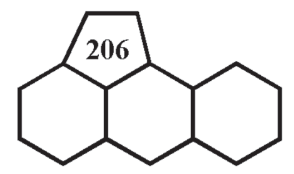

$\mathrm{A}_{2}$

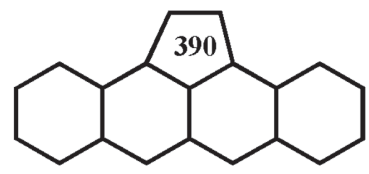

$A_{4}$
Fig. 4. The energy effects (ef) of the five-membered ring of some acenaphthylenes. The ef-values in the

five-membered rings are multiplied by 10000 .

If we compare the values for the energy effects of the five-membered rings in examples from Figure 4, we see that compounds $A_{2}$ and $A_{3}$ have two times larger values for the energy effect than compound $A_{1}$. In compound $A_{4}$ value for the energy effect is more then three times greater than in compound $A_{1}$.

A fully analogous variation of the extent of cyclic conjugation in the five-membered ring, but somewhat weaker, was found in the case of fluoranthenes. Examples are shown in Figure 5.
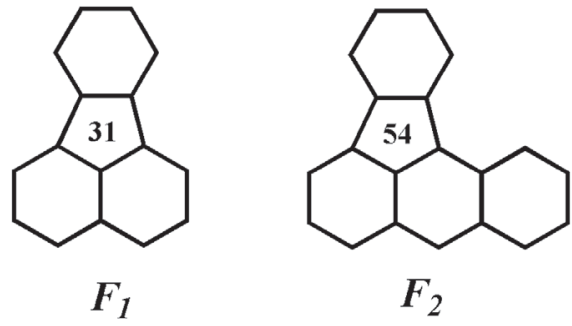

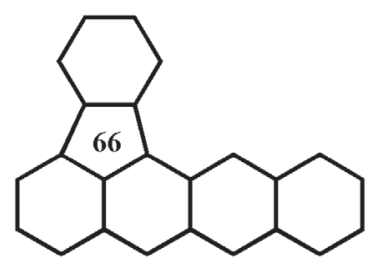

$F_{3}$

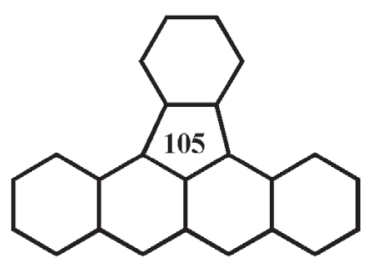

$F_{4}$
Fig. 5. The energy effects (ef) of the five-membered ring of some fluoranthenes. The ef-values in the fivemembered rings are multiplied by 10000 .

If we compare the values for the energy effect of the five-membered ring in compounds $F_{2}$ and $F_{3}$ we see that these have two times greater values than in compound $F_{1}$. Compound $F_{4}$ has three times greater value for the energy effect than compound $F_{1}$.

Analyzing the examples from Figures 4 and 5, one major structural factor affecting the energy effects of five-membered ring can be recognized. When the six-membered ring is connected to the five-membered ring with exactly one carbon-carbon bond we say that these two rings are in a phenyl-cyclopentadienyl (PCP) constellation. In Figure 6 four examples are depicted in which the PCP constellations are indicated. From these examples one can see that there can be more than one PCP constellation. We now can state the observed regularity for the cyclic conjugation in acenaphthylenes and fluoranthenes as follows:

The PCP rule: If the five-membered ring of an acenaphthylene or fluoranthene congener is in a PCP constellation with a six-membered ring, then the intensity of its cyclic conjugation (measured by its energy effect) is much greater than the analogous effect in congeners of similar structure with no PCP constellations. The greater is the number of PCP constellations, the greater is the respective increase of the energy effect. 


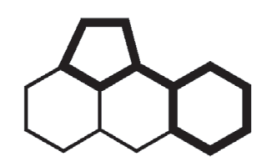

A

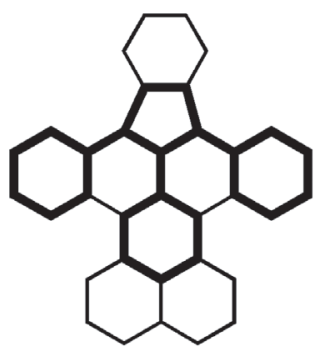

F

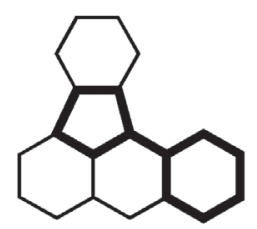

F

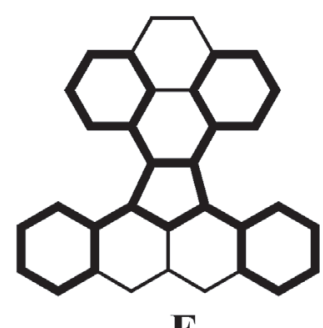

F
Fig. 6. The structural features referred to as phenylcyclopentadienyl (PCP) constellations are indicated by heavy lines; the diagrams marked by $A$ and $F$ are acenaphthylene and fluoranthene derivatives, respectively.
The validity of the PCP rule was checked on several hundreds of acenaphthylenes and fluoranthenes, by calculating the values of the energy effects of all their rings. A characteristic group of congeners examined is shown in Figure 7 and Table 1 and their ef-values in Table 2. Not a single violation of the PCP rule was observed. Based on our extensive numerical work, we are inclined to conclude, that the PCP rule is a generally applicable regularity. Although cyclic conjugation in the five-membered ring in fluoranthenes is small and its intensity is more than one order of magnitude smaller than in other rings, it is not negligibly small and its intensity increases with increasing number of PCP constellations.

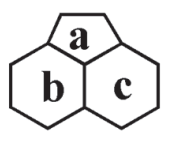

$A_{1}$

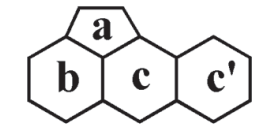

$A_{2}$

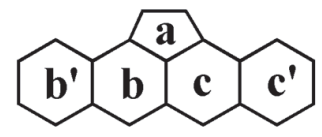

$A_{3}$

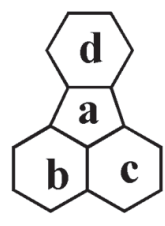

$F_{1}$

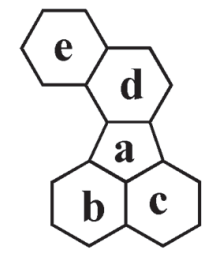

$F_{2}$
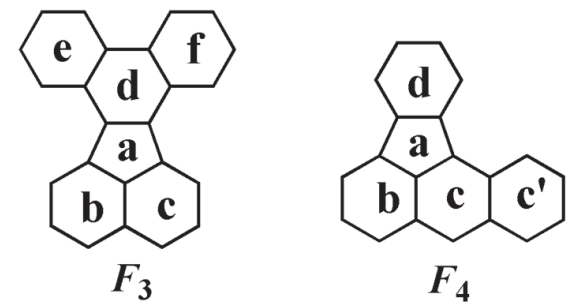

$F_{4}$

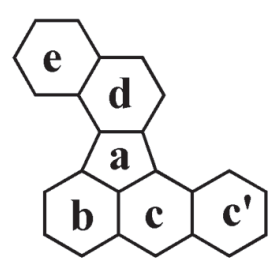

$F_{5}$

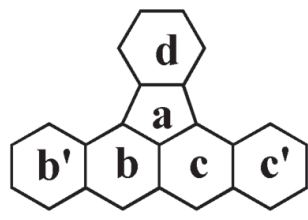

$F_{8}$

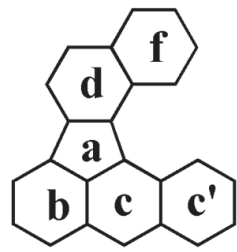

$F_{6}$

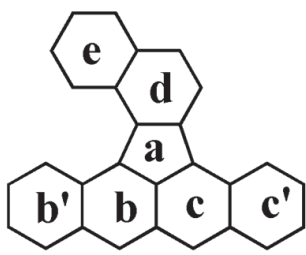

$F_{9}$

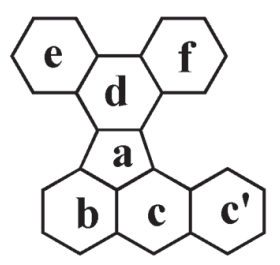

$F_{7}$

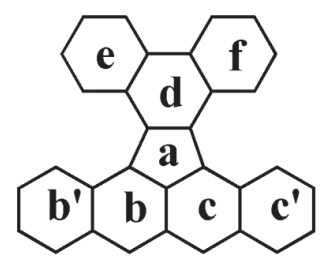

$F_{10}$

Fig. 7. Acenaphthylenes and fluoranthenes whose $e f$-values are given in Table 2 
Ta b 1 e 1

IUPAC names (along with the trivial names, when they exist) and CAS numbers, of the compounds considered in this review. Note that in some cases these names are not unique. For instance, $F_{8} c a n$ be names as indeno[1,2,3-fg]naphthacene or 5,6-(1,2-phenylene)naphthacene or 5,6-o-phenylnaphthacene [30]

\begin{tabular}{cccr}
\hline \hline Comp. & Trivial name & IUPAC name & CAS \# \\
\hline$A_{1}$ & acenaphthylene & acenaphthylene & $208-96-8$ \\
$A_{2}$ & aceanthrylene & aceanthrylene & $202-03-9$ \\
$A_{3}$ & - & benz $[d]$ aceanthrylene & $199770-52-6$ \\
$F_{1}$ & fluoranthene & fluoranthene & $206-44-0$ \\
$F_{2}$ & - & benzo[j]fluoranthene & $205-82-3$ \\
$F_{3}$ & - & dibenzo[j,l]fluoranthene & $203-18-9$ \\
$F_{4}$ & - & benzo $[a]$ fluoranthene & $203-33-8$ \\
$F_{5}$ & - & dibenzo $[a, j]$ fluoranthene & $75519-75-4$ \\
$F_{6}$ & - & dibenzo $[a, l]$ fluoranthene & - \\
$F_{7}$ & - & tribenzo $[a, j, l]$ fluoranthene & - \\
$F_{8}$ & - & dibenzo $[a, f]$ fluoranthene & $203-11-2$ \\
$F_{9}$ & - & tirbenzo $[a, f, j]$ fluoranthene & - \\
$F_{10}$ & - & tetrabenzo $[a, f, j, l]$ fluoranthene & - \\
\hline \hline
\end{tabular}

Table 2

The energy effects (in $\beta$ units) of all rings of acenaphthylenes and fluoranthenes depicted in Figure 7. For the numbering of the compounds (comp.) and labelling of the rings see Figure 7; $\# P C P=$ number of PCP constellations.

\begin{tabular}{cccccccccc}
\hline Comp. & $\# P C P$ & $e f(\mathbf{a})$ & $e f(\mathbf{b})$ & $e f(\mathbf{c})$ & $e f(\mathbf{d})$ & $e f(\mathbf{e})$ & $e f(\mathbf{f})$ & $e f\left(\mathbf{b}^{\prime}\right)$ & $e f\left(\mathbf{c}^{\prime}\right)$ \\
\hline$A_{1}$ & 0 & 0.0114 & 0.1050 & 0.1050 & - & - & - & - & - \\
$A_{2}$ & 1 & 0.0206 & 0.0809 & 0.0527 & - & - & - & - & 0.1128 \\
$A_{3}$ & 2 & 0.0390 & 0.0411 & 0.0411 & - & - & - & 0.1154 & 0.1154 \\
$F_{1}$ & 0 & 0.0031 & 0.1120 & 0.1120 & 0.2229 & - & - & - & - \\
$F_{2}$ & 1 & 0.0043 & 0.1116 & 0.1090 & 0.0957 & 0.1294 & - & - & - \\
$F_{3}$ & 2 & 0.0056 & 0.1089 & 0.1089 & 0.0408 & 0.1650 & 0.1650 & - & - \\
$F_{4}$ & 1 & 0.0054 & 0.0884 & 0.0579 & 0.2102 & - & - & - & 0.1059 \\
$F_{5}$ & 2 & 0.0080 & 0.0856 & 0.0572 & 0.0903 & 0.1314 & - & - & 0.1078 \\
$F_{6}$ & 2 & 0.0079 & 0.0886 & 0.0557 & 0.0900 & - & 0.1327 & - & 0.1089 \\
$F_{7}$ & 3 & 0.0105 & 0.0859 & 0.0553 & 0.0385 & 0.1662 & 0.1683 & - & 0.1101 \\
$F_{8}$ & 2 & 0.0105 & 0.0468 & 0.0468 & 0.1911 & - & - & 0.1048 & 0.1048 \\
$F_{9}$ & 3 & 0.0159 & 0.0462 & 0.0447 & 0.0821 & 0.1361 & - & 0.1078 & 0.1089 \\
$F_{10}$ & 4 & 0.0211 & 0.0444 & 0.0444 & 0.0353 & 0.1708 & 0.1708 & 0.1110 & 0.1110 \\
\hline \hline
\end{tabular}


With regard to Figure 7 and Table 2, the PCP rule is convincingly illustrated by following data: ef $\left(F_{1}, \mathrm{a}\right)=0.0031$ (no PCP constellations); ef $\left(F_{4}, \mathrm{a}\right)=0.0054$, ef $\left(F_{2}, \mathrm{a}\right)=0.0043$ (one PCP constellation); ef $\left(F_{5}, \mathrm{a}\right)=0.0080$, ef $\left(F_{8}, \mathrm{a}\right)=0.0105$ (two PCP constellations); ef $\left(F_{7}, \mathrm{a}\right)=0.105 ;$ ef $\left(F_{9}, \mathrm{a}\right)=0.0159$ (three PCP constellations); ef $\left(F_{10}, \mathrm{a}\right)=0.0211$ (four PCP constellations). These examples imply that PCP constellation increases the magnitude of cyclic conjugation in the five-membered ring and the greater the number of PCP constellations, the greater is the $e f$-value of the five-membered ring.

Recently, the validity of the PCP rule, based on the energy effects calculated by means of Eq. (1), was demonstrated in a mathematically rigorous manner $[31,32]$.

\section{TESTING THE PCP RULE}

Nowadays, there is no doubt that the PCP rule, as formulated on the basis of ef-values, is a generally valid regularity for cyclic conjugation in acenaphthylene and fluoranthene congeners. On the other hand, because the ef-method is based on an approximate molecular-orbital model [14, 15], the results obtained by applying Eq. (1) cannot be considered as absolutely correct and undeniable. In other words, the question remains whether the PCP rule is just a mathematical artefact of the model, or it is a real and objectively existing chemical phenomenon. In order eliminate (or possibly confirm) such doubts, a number of tests of the PCP rule had been undertaken, all based on different models and different theoretical approaches. These are summarized in the present section.

According to the PCP rule, a benzo-annelation in PCP constellation increases the magnitude of cyclic conjugation in the five-membered ring. If so, then the bond order of the carboncarbon bonds $x$ and $y$ in acenaphthylenes and fluoranthenes should increase, whereas the order of the bond $z$ in acenaphthylenes should decrease (cf. Figure 2). Consequently, the length of $x$ and $y$ should decrease, and the length of $z$ increase. Such changes in bond order and bond length could be checked by methods independent of the ef-model.

\subsection{Wiberg bond order and bond length}

We have tested the PCP-rule by means of an independent methodology based on a highly reliable quantum chemical approach, namely ab initio DFT calculations [33]. All calculations were done by using of the Gaussian $03 \mathrm{~W}$ package, version 6.1, at the B3LYP/6-31G(d) level of theory [34]. Optimized geometries were determined for all considered molecules. Note that the molecules $F_{6}, F_{7}, F_{9}$, and $F_{10}$ (cf. Figure 7) are non-planar, whereas all other molecules studied were found to be planar. The planarity/ non-planarity of the considered molecules does not effect the conclusions outlined in the present section. For testing the PCP rule we calculated Wiberg bond orders and bond lengths [35].

It is important to recall that the Wiberg bond order (WBO) is equal to 1 for a purely single carbon-carbon bond and equal to 2 for a purely double carbon-carbon bond. When the carbon-carbon bond is aromatic then its Wiberg bond order will assume a value between 1 and 2 , the closer to 2 the stronger is the $\pi$-electron conjugation [35].

According to the classical theories [12, 13], the bonds $x$ and $y$ are single in all Kekule structures of acenaphthylenes and fluoranthenes, whereas bond $\mathrm{z}$ is double in all Kekulé structures of acenaphthylenes (see Figures 2 and 3). Therefore, if the PCP rule is valid, the Wiberg bond orders of the single bonds $x$ and $y$ should increase with the increasing number of PCP constellations. At the same time, the Wiberg bond order for the double bonds $z$ should decrease with the increase number of PCP constellations. We show, that this is indeed the case, by examine the same molecules that were examined by energy effects. The results for Wiberg bond orders for acenaphthylenes and fluoranthenes from Figure 7 are depicted in Table 3. 


\section{Table 3}

Wiberg bond orders (WBO) of the bonds $x, y$, and $z$ of acenaphthylenes and fluoranthenes depicted in Figure 7; see also Figure 2. \#PCP is the number of PCP constellations contained in the respective molecule.

\begin{tabular}{ccccc}
\hline \hline Comp. & $\# P C P$ & $W B O(x)$ & WBO(y) & WBO(z) \\
\hline$A_{1}$ & 0 & 1.1003 & 1.1003 & 1.7482 \\
$A_{2}$ & 1 & 1.1096 & 1.1114 & 1.7284 \\
$A_{3}$ & 2 & 1.1255 & 1.1255 & 1.7016 \\
$F_{1}$ & 0 & 1.0703 & 1.0703 & - \\
$F_{2}$ & 1 & 1.0744 & 1.0783 & - \\
$F_{3}$ & 2 & 1.0770 & 1.0770 & - \\
$F_{4}$ & 1 & 1.0755 & 10810 & - \\
$F_{5}$ & 2 & 1.0865 & 1.0855 & - \\
$F_{6}$ & 2 & 1.0814 & 1.0896 & - \\
$F_{7}$ & 3 & 1.0867 & 1.0878 & - \\
$F_{8}$ & 2 & 1.0900 & 1.0900 & - \\
$F_{9}$ & 3 & 1.0970 & 1.1031 & - \\
$F_{10}$ & 4 & 1.1028 & 1.1028 & - \\
\hline \hline
\end{tabular}

The PCP rule will be confirmed if acenaphthylenes and fluoranthenes obey the following relations:

$$
\begin{aligned}
\# P C P\left(A_{i}\right)>\# P C P\left(A_{j}\right) \Rightarrow & W B O\left(x \mid A_{i}\right)>W B O\left(x \mid A_{j}\right) \\
& W B O\left(y \mid A_{i}\right)>W B O\left(y \mid A_{j}\right) \\
& W B O\left(z \mid A_{i}\right)<W B O\left(z \mid A_{j}\right)
\end{aligned}
$$

for acenaphthylenes, and

$$
\begin{aligned}
\# P C P\left(F_{i}\right)>\# P C P\left(F_{j}\right) \Rightarrow & W B O\left(x \mid F_{i}\right)>W B O\left(x \mid F_{j}\right) \\
& W B O\left(y \mid F_{i}\right)>W B O\left(y \mid F_{j}\right)
\end{aligned}
$$

for fluoranthenes. By $\mathrm{WBO}(q \mid M)$ we denote the Wiberg bond order of the bond $q$ in the molecule $M$. By \#PCP we denote the number of PCP constellations.

From Table 3 one can see that acenaphthylenes obey Eq. (2a) without a single exception.
In particular, the Wiberg bond order of $x$ and $y$ is minimal and of $z$ maximal for $A_{1}$, the molecule without any PCP constellation. For $A_{3}$, the molecule with two PCP constellations, the Wiberg bond order is maximal for bonds $x$ and $y$, and minimal for bond $z$. Also the majority of the fluoranthenes from Figure 7 satisfy Eq. (2b), in this way confirming the PCP rule. In particular, the Wiberg bond order of $x$ and $y$ is minimal for $F_{1}$, the molecule without any PCP constellation, and the WBO of $x$ and $y$ is maximal for $F_{10}$, the molecule with four PCP constellations.

The second test that we used to check the PCP rule is the bond length of the bonds $x$, $y$ in acenaphthylenes and fluoranthenes and of the bond $z$ in acenaphthylenes. Our expectation was that with the increase of the intensity of cyclic conjugation in the five-membered ring, the length of the $x$ and $y$ carbon-carbon bonds (single in Kekulé structures) will decrease, whereas the length of the double bond $z$ will increase. In accordance with this, the PCP rule will be valid if our molecules obey the following equations:

$$
\begin{aligned}
& \# P C P\left(A_{i}\right)>\# P C P\left(A_{j}\right) \Rightarrow d\left(x \mid A_{i}\right)<d\left(x \mid A_{j}\right) \\
& d\left(y \mid A_{i}\right)<d\left(y \mid A_{j}\right) \\
& d\left(z \mid A_{i}\right)>d\left(z \mid A_{j}\right) \\
& \# P C P\left(F_{i}\right)>\# P C P\left(F_{j}\right) \Rightarrow d\left(x \mid F_{i}\right)<d\left(x \mid F_{j}\right) \\
& d\left(y \mid F_{i}\right)<d\left(y \mid F_{j}\right)
\end{aligned}
$$

for fluoranthenes. By $d(q \mid M)$ we denote the length of the bond $q$ in the molecule $M$. By \#PCP we denote the number of PCP constellations.

The calculated lengths of the bonds $x, y$, and $z$ for the molecules from Figure 7 are given in Table 4. By direct inspection of the data in Table 4 one can see that acenaphthylenes obey Eq. (3a) in all cases. Therefore, in the case of acenaphthylenes, the PCP rule is fully confirmed by our second test (bond length). 
$\mathrm{T}$ a b 1 e 4

Length of the carbon-carbon bonds $x, y$, and $z$ of the acenaphthylenes and fluoranthenes depicted in Figure 7; see also Figure 2. $\# P C P$ is the number of PCP constellations in the respective molecule.

\begin{tabular}{ccccc}
\hline \hline Comp. & $\# P C P$ & $d(x)(\mathrm{pm})$ & $d(y)(\mathrm{pm})$ & $\begin{array}{c}d(z) \\
(\mathrm{pm})\end{array}$ \\
\hline$A_{1}$ & 0 & 147.3 & 147.3 & 136.4 \\
$A_{2}$ & 1 & 146.8 & 147.1 & 136.6 \\
$A_{3}$ & 2 & 146.5 & 146.5 & 136.9 \\
$F_{1}$ & 0 & 147.6 & 147.6 & - \\
$F_{2}$ & 1 & 147.1 & 148.3 & - \\
$F_{3}$ & 2 & 148.3 & 148.3 & - \\
$F_{4}$ & 1 & 146.9 & 148.2 & - \\
$F_{5}$ & 2 & 147.6 & 147.9 & - \\
$F_{6}$ & 2 & 146.4 & 149.1 & - \\
$F_{7}$ & 3 & 147.4 & 148.6 & - \\
$F_{8}$ & 2 & 147.5 & 147.5 & - \\
$F_{9}$ & 3 & 147.1 & 147.9 & - \\
$F_{10}$ & 4 & 147.6 & 147.6 & - \\
\hline \hline
\end{tabular}

The lengths of the bonds $x$ and $y$ in fluoranthenes are found to depend on the steric repulsion between the near-lying hydrogen atoms, especially those indicated in Figure 8. Because of this steric repulsion, testing the PCP rule is slightly more complicated. For instance, the $\delta$-type of bond $y$ in molecule $F_{6}$ is somewhat longer than the $\alpha$-type of bond $x$ in the same molecule; $d\left(x \mid F_{6}\right)=146.4 \mathrm{pm}, d\left(y \mid F_{6}\right)$ $=149.1 \mathrm{pm}$. This extension of bond $y$ (relative to bond $x$ ) is evidently the consequence of the need to make enough space for two near-lying hydrogen atoms. In accordance with this, the test conditions should be applied only to bonds $x$ and $y$ of the same type $\alpha, \beta, \gamma$, or $\delta$, as indicated in Figure 8. When the test is applied in this way, the results are the accordance with the PCP rule. Thus, in summary we conclude [33] that highly accurate quantum chemical calculations of molecular geometry confirm that the PCP rule is not an artifact but a real chemical phenomenon.
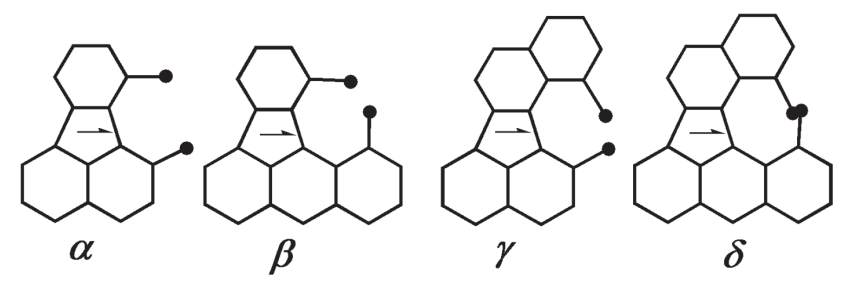

Fig. 8. Four types of carbon-carbon bonds (marked by arrows) in fluoranthenes, whose length is influenced by the repulsion between near-lying hydrogen atoms (marked by heavy dots). These steric interactions increase of the length of the respective carbon-carbon bonds. In case $\delta$ the carbon-atom skeleton cannot be planar, in spite of the erroneous claim in Ref. [33].

\subsection{Multicenter delocalization indices}

Multicenter delocalization indices [36, 37] were also used as one of the criteria for testing the PCP rule [38]. Multicenter bond indices are aimed at measuring the extent to which the electrons are delocalized among a set of $n$ atoms. For our test we used the five-center bonding index (5-CBI). This index is related to the five carbon atoms (labeled as $A, B, C, D$, and $E$ ) of the five-membered ring in acenaphthylenes and fluoranthenes. The five-center index, characterizing the extent of the cyclic conjugation in a particular five-membered ring, is defined as:

$$
\begin{aligned}
5-C B I & =2^{2} \Delta_{A B C D E}^{J}=\sum_{\mu \in A} \sum_{\nu \in B} \sum_{\lambda \in C} \sum_{\kappa \in D} \sum_{\xi \in E} \sum_{i} T_{i} \\
\cdot & {\left[(P S)_{\mu \nu}(P S)_{\nu \lambda}(P S)_{\lambda \kappa}(P S)_{\mathcal{K} \xi}(P S)_{\xi \mu}\right] }
\end{aligned}
$$

where $P$ is the charge/bond-order matrix and $S$ the overlap matrix. The summation runs over all basis functions $\mu, v, \lambda, \kappa, \xi$ centered on the atoms $A-E$ involved in a given ring. $\Gamma$ is the permutation operator that takes into account all possible $(=5$ !) permutations of the atomic labels. Calculation of the five-center bond indices was performed at the HMO level of theory. Within that approach, the overlap matrix is a unit matrix and equation (4) is reduces to: 


$$
\begin{aligned}
& 5-C B I=2^{2} d_{A B C D E}^{(5)}=\sum_{\mu \in A} \sum_{v \in B} \sum_{\lambda \in C} \sum_{k \in D} \sum_{\xi \in E} \sum_{i} F_{i} \\
& \cdot\left[P_{\mu \nu}{ }^{P} v \lambda{ }^{P} \lambda{ }^{P} P_{K \xi} P_{\xi \mu}\right]
\end{aligned}
$$

The greater the value for the five-center index, the greater is the intensity of cyclic conjugation in the five-membered ring. Values for the five-center index were calculated for the five-membered rings of all acenaphthylenes and fluoranthenes depicted in Figure 7. These data, together with respective energy effects, are given in Table 5.

\section{Table 5}

The five-center index (5-CBI) and energy effect (ef) of the five-membered ring of acenaphthylenes and fluoranthenes depicted in Figure 7, as well as the respective ring currents. As usual, the dimensionless numerical value of ring currents is given relative to the ring current of benzene.

$\# P C P$ is the number of PCP constellations in the respective molecule.

\begin{tabular}{ccccc}
\hline \hline Comp. & \# PCP & 5-CBI & ef & $\begin{array}{c}\text { Ring } \\
\text { currents }\end{array}$ \\
\hline$A_{1}$ & 0 & 0.5250 & 0.0114 & 0.103 \\
$A_{2}$ & 1 & 0.6124 & 0.0206 & 0.184 \\
$A_{3}$ & 2 & 0.7281 & 0.0390 & 0.333 \\
$F_{1}$ & 0 & 0.2685 & 0.0031 & 0.050 \\
$F_{2}$ & 1 & 0.3096 & 0.0043 & 0.063 \\
$F_{3}$ & 2 & 0.3457 & 0.0056 & 0.073 \\
$F_{4}$ & 1 & 0.3062 & 0.0054 & 0.092 \\
$F_{5}$ & 2 & 0.3558 & 0.0080 & 0.121 \\
$F_{6}$ & 2 & 0.3559 & 0.0079 & 0.119 \\
$F_{7}$ & 3 & 0.3994 & 0.0105 & 0.138 \\
$F_{8}$ & 2 & 0.3566 & 0.0105 & 0.184 \\
$F_{9}$ & 3 & 0.4181 & 0.0159 & 0.240 \\
$F_{10}$ & 4 & 0.4716 & 0.0211 & 0.273 \\
\hline \hline
\end{tabular}

Results from Table 5 show that the fivecenter index is in perfect agreement with the PCP rule. For instance, for acenaphthylenes
$A_{2}$ and $A_{3}$ (possessing, respectively one and two PCP constellations) the five-bond indices are 0.6124 and 0.7281 , respectively. Among the fluoranthenes from Figure 7, minimum and maximum for the five-center index have, respectively, $F_{1}$ with no PCP constellation and $F_{13}$ with four PCP constellations; 5-CBI $\left(F_{1}\right)=$ $0.2685,5-\mathrm{CBI}\left(F_{13}\right)=0.4716$.

The analysis preformed by employing multicenter bond indices as a method for testing our rule clearly indicates that the PCP rule reflects some real feature of the $\pi$-electron distribution in the respective molecule. From Figure 9 it can be established that a reasonably good correlation between the five-center indices and the energy effects exists. Not surprisingly, the data-points for acenaphthylene and fluoranthene congeners lie on two different lines. This implies not only that the PCP rule is convincingly confirmed by multicenter bond indices, but also that these two different methods for measuring cyclic conjugation are in quantitative agreement.

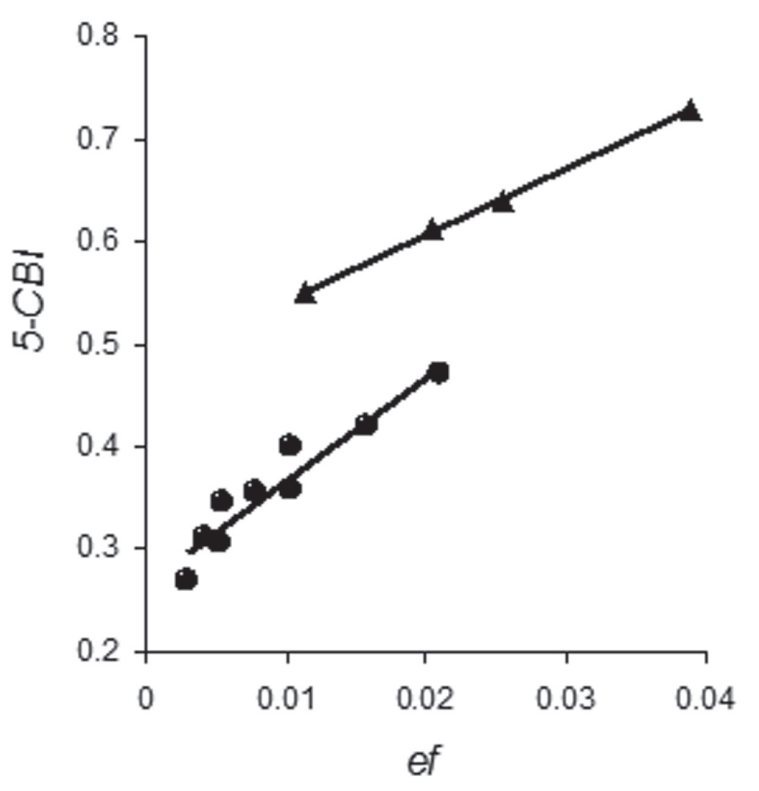

Fig. 9. Five-center bond indices (5-CBI) vs. energy effects (ef) for the acenaphthylenes (triangles) and fluoranthenes (circles) depicted in Figure 7. 


\subsection{Ring-currents}

Ring currents [39, 40] are induced in polycyclic conjugated molecules by means of an external magnetic field. They provide a measure of the flow of $\pi$-electrons in the respective ring, and in a natural manner, can be related to the intensity of cyclic conjugation in this ring [40]. Ring currents examined by us are purely graph-theoretical quantities, reliant solely on the knowledge of the vertex-adjacency matrix and the number of vertices. These are calculated by the Hückel-London-Pople-McWeeny method using the computer programs NPRC and MPRC [41].

The calculated values for ring currents [42] of acenaphthylenes and fluoranthenes from Figure 7 are given in Table 5.

Topological ring currents imply that cyclic conjugation in the five-membered ring of the considered acenaphthylenes and fluoranthenes is weak, same as their energy effects. (Recall that the ring current of benzene is set to be equal to 1.0000.) From Table 5 we see that ring currents are in fact in perfect agree- ment with the PCP rule. The best examples are the two acenaphthylenes, $A_{1}$ (no PCP constellations) and $A_{3}$ (two PCP constellations) for which the values for ring currents are 0.103 and 0.333 , respectively. Illustrative examples for fluoranhtens are molecules $F_{1}$ (no PCP constellation), $F_{4}$ (one PCP constellation), $F_{8}$ (two PCP constellations), $F_{9}$ (three PCP constellations) and $F_{10}$ (four PCP constellations); the ring currents in their five-membered ring are 0.050, $0.092,0.184$, and 0.273 , respectively.

Thus it can be seen that criteria based on ring currents provide a further (independent) confirmation of the PCP rule.

\subsection{NICS method}

NICS is an acronym from Nucleus Independent Chemical Shift [43, 44]. This method is based on the fact that delocalized $\pi$-electrons produce a relatively high diamagnetic ring current under an external magnetic field. In the NICS method a ghost atom (no nucleus, no basis function) is placed at a desired point in the

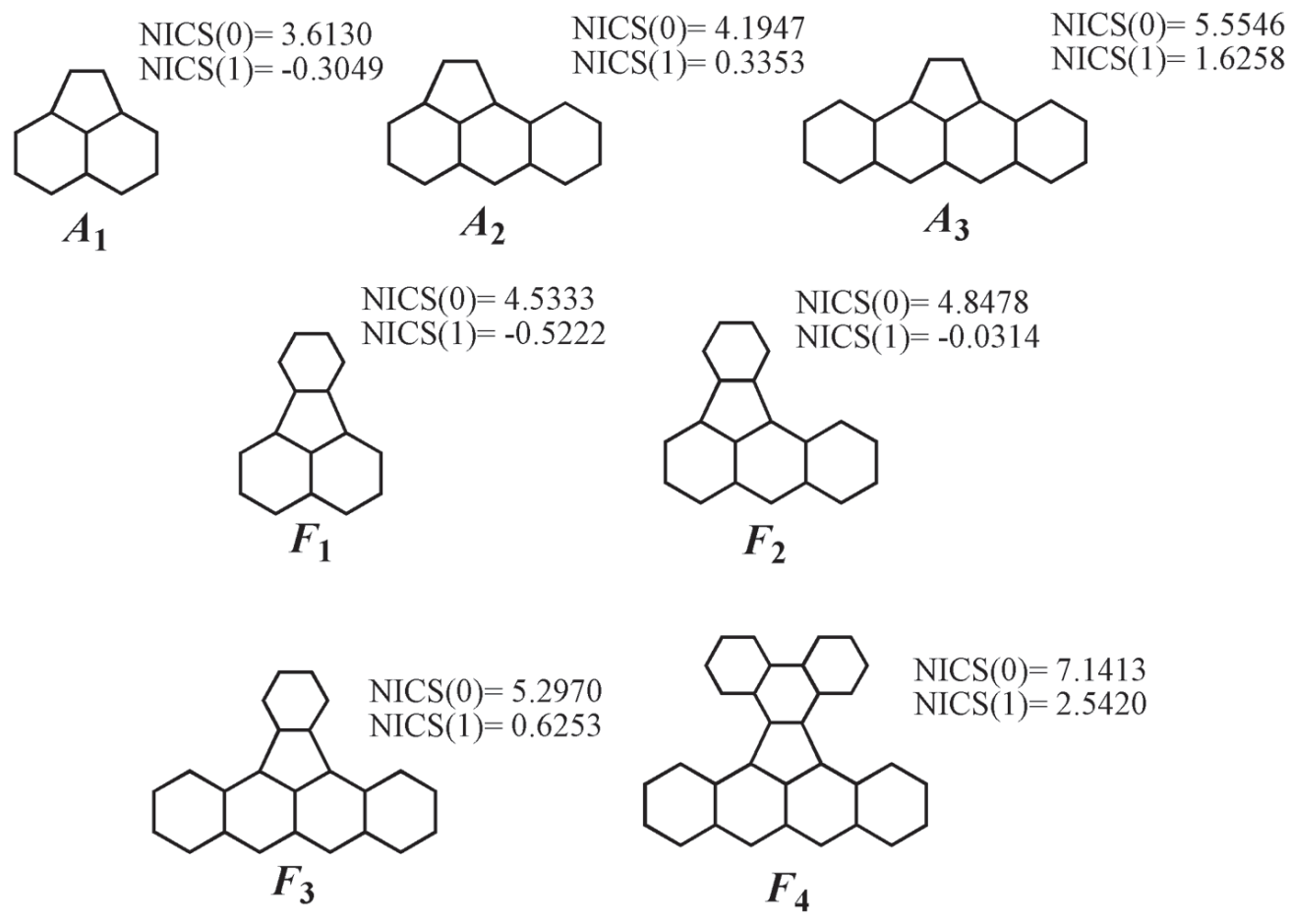

Fig. 10. Some acenaphthylenes and fluoranthenes and the nucleus independent chemical shift NICS(0) and NICS(1) values pertaining to their five-membered rings 
space. The chemical shift of the ghost atom can be calculated, thus indicating the chemical environment of this atom. A ghost atom placed in the center of aromatic or antiaromatic ring senses the induced diamagnetic or paramagnetic ring current, respectively. Negative NICS values indicate aromaticity of a ring, while positive NICS values indicate antiaromaticity of a ring. Calculations reported here were performed using the gauge invariant atomic orbital (GIAO) approach at the B3LYP/6-311G(d, p) level of theory. For testing the PCP rule we calculated $\operatorname{NICS}(0)$ and NICS(1). NICS(0) means that the ghost atom is placed at the center of the ring and NICS(1) means that the ghost atom is placed at $1 \AA$ above the ring. At the center of the aromatic ring $\sigma$-electrons may have a high density and in that way contribute to the chemical shift. With NICS(1) this complicated influences are reduced and thus NICS(1) is recommended as being a better measure of the $\pi$-electron delocalization compared to $\mathrm{NICS}(0)$. It should be mentioned that in our test we do not intend to measure aromaticity in acenaphthylenes and fluoranthenes. The goal of this test is to demonstrate that there is some cyclic conjugation in these molecules and that rings in PCP constellations influence it. By examining the NICS values we found the result to be a kind of surprise, because these indices show a regularity that does not agree with what would be expected on the basis of the PCP rule.

From Figure 10 one can see that the NICS values precisely follow the PCP rule but in opposite direction with regard to energy effects. We assumed that, because negative NICS values indicate aromaticity, with increasing number of PCP constellations the values for NICS indices would decrease. But, as examples from Figure 10 show, the situation is exactly opposite. Indeed, $F_{1}$ has the lowest values for NICS indices and this molecule does not have any PCP constellation. On the other hand, $F_{4}$ has the greatest values for NICS indices and it has four PCP constellations. The same happens for acenaphthylenes: A1 has the lowest values for NICS (no PCP constellation) and $A_{3}$ has the greatest values for NICS (two PCP constellations). According to this criterion, six-membered rings in $\mathrm{PCP}$ constellation decrease the aromaticity of the five-membered ring. The NICS method has, in some way, confirmed that rings in PCP constellations influence the cyclic conjugation in the five-membered ring, but in an opposite sense as the PCP rule would require.

At this moment we do not possess a sound explanation for this disagreement. We only note that it is well known that local aromaticity predicted by NICS and by thermochemical approaches differs in many cases, hinting towards a conclusion that energetic and magnetic criteria reflect different and independent aspects of aromaticity [45].

\section{CONCLUSION}

For the purpose of better understanding the $\pi$-electron properties of acenaphthylenes and fluoranthenes, a systematic study of their cyclic conjugation was undertaken. In our opinion, we discovered a new general regularity, named by us the phenyl-cyclopentadienyl rule, or shorter the PCP rule. According to this rule, six membered rings in PCP constellation (cf. Figure 6) increase the magnitude of cyclic conjugation in the five-membered ring. The greater is the number of such six-membered rings, the stronger is the cyclic conjugation in the five-membered ring.

Initially, this regularity was established by studying the energy effects of individual rings (cf. Eq. (1)), but was eventually corroborated by means of several other independent approaches (Wiberg bond orders, carbon-carbon bond lengths calculated by high-level $a b$ initio DFT methods, multicenter delocalization indices, ring currents). The only disagreement found was by testing the PCP rule by means of NICS.

It is important to note that the PCP rule cannot be rationalized by means of the "classical" theories of cyclic conjugation, based on considerations of Kekulé or Clar structures. 
The PCP rule seems to be generally valid for acenaphthylene and fluoranthene congeners, but its extension to other PAHs containing five-membered rings was not successful $[46,47]$. On the other hand, a regularity fully analogous to the PCP rule holds in acenaphthylene- and fluoranthene-type systems in which the odd-membered ring has size different than five [48].

We have established several other regularities related to the PCP rule [27-29], in particular those concerned with the effect of benzo-annelation that is not in PCP constellation. A detailed discussion of these topics goes beyond the ambits of the present review.

Acknowledgement. The authors thank for support by the Serbian Ministry of Science (Grant No. 174033). The authors also thank the anonymous referee for pointing out the non-planarity of the molecules $F_{6}, F_{7}, F_{9}$, and $F_{10}$ and for helping them to eliminate the error occurring in Ref. [33].

\section{REFERENCES}

[1] M. Zander, Polycyclische Aromaten, Teubner, Stuttgart, 1995.

[2] R. G. Harvey, Polycyclic Aromatic Hydrocarbons, Wiley-VCH, New York, 1997.

[3] E. B. Ledesma, M. A. Kalish, M. J. Wornat, P. F. Nelson, J.C. Mackie, Observation of cyclopentafused and ethynyl-substituted PAH during the fuel-rich combustion of primary tar from a bituminous coal, Energy Fuels 13, 1167-1172 (1999).

[4] A. Necula, L. T. Scott, High temperature behavior of alternant and nonalternant polycyclic aromatic hydrocarbons, J. Anal. Appl. Pyrol. 54, 65-87 (2000).

[5] M. J. Otero-Lobato, V. E. Kaats-Richters, C. Koper, E. J. Vlietstra, R.W. Havenith, L.W. Jenneskens, W. Seinen, CP-arene oxides: the ultimate, active mutagenic forms of cyclopenta-fused polycyclic aromatic hydrocarbons (CP-PAHs), Mutat. Res. 581, 115-132 (2005).

[6] C. Gooijer, I. Kozin, N. H. Velthorst, M. Sarobe, L. W. Jenneskens, The Sphol'skii fluorescence spectrum of cyclopenta[c,d]pyrene. Novel evi- dence for anomalous S2-emission, Spectrochim. Acta A54, 1443-1449 (1998).

[7] I. Gutman, J. Đurđević, Fluoranthen and its congeners - A graph theoretical study, MATCH Commun. Math. Comput. Chem. 60, 659-670 (2008).

[8] I. Gutman, J. Đurđević, D. Bašić, D. Rašović, On $\pi$-electron configuration of cyclopenta-derivatives of benzenoid hydrocarbons, Indian J. Chem. 49A, 853-860 (2010).

[9] I. Gutman, J. Đurđević, Cycles in dicyclopentaderivatives of benzenoid hydrocarbons, MATCH Commun. Math. Comput. Chem. 65, 785-798 (2011).

[10] J. R. Dias, Resonance topology of fluorenthenoid/ fluorenoid hydrocarbons and related systems, $\mathrm{Po}-$ lyc. Arom. Comp. 31, 48-60 (2011).

[11] J. R. Dias, Handbook of Polycyclic Hydrocarbons. Part A. Benzenoid Hydrocarbons, Elsevier, Amsterdam, 1987.

[12] I. Gutman, S. J. Cyvin, Introduction to the Theory of Benzenoid Hydrocarbons, Springer, Berlin, 1989.

[13] M. Randić, Aromaticity of polycyclic conjugated hydrocarbons, Chem. Rev. 103, 3449-3606 (2003).

[14] I. Gutman, Cyclic conjugation energy effects in polycyclic $\pi$-electron systems, Monatsh. Chem. 136, 1055-1069 (2005).

[15] I. Gutman, Mathematical modeling of chemical phenomena, in: A. Graovac, I. Gutman, D. Vukičević (Eds.), Mathematical Methods and Modelling for Students of Chemistry and Biology, Hum, Zagreb, 2009, pp. 13-27.

[16] I. Gutman, Ž. Tomović, On cyclic conjugation of the members of the pyrene/peropyrene series and their formally $\pi$-localized derivatives, Bull. Chem. Technol. Maced. 20, 33-37 (2001).

[17] I. Gutman, S. Stanković, Why is phenanthrene more stable than anthracene? Maced. J. Chem. Chem. Eng. 26, 111-114 (2007).

[18] S. Jeremić, S. Radenković, I. Gutman, Cyclic conjugation in benzo-annelated coronenes, Maced. $J$. Chem. Chem. Eng. 29, 63-69 (2010).

[19] I. Gutman, B. Stojanovska, Effect of benzocyclobutadieno-annelation on cyclic conjugation in perylene, Maced. J. Chem. Chem. Eng. 30, 235-240 (2011). 
[20] I. Gutman, O. E. Polansky, Mathematical Concepts in Organic Chemistry, Springer, Berlin, 1986.

[21] Gutman, Uvod u hemijsku teoriju grafova, PMF Kragujevac, Kragujevac, 2003.

[22] J. Đurđević, S. Radenković, I. Gutman, Hall rule in fluorenthene-type benzenoid hydrocarbons, $J$. Serb. Chem. Soc. 73, 989-995 (2008).

[23] I. Gutman, J. Đurđević, S. Radenković, A. Burmudžija, Energetic properties of fluoranthenes, Indian J. Chem. 48A, 194-197 (2009).

[24] I. Gutman, Kekulé structures in fluoranthenes, $Z$. Naturforsch. 65a, 473-476 (2010).

[25] D. Vukičević, J. Đurđević, I. Gutman, On the number of Kekulé structures of fluoranthene congeners, J. Serb. Chem. Soc. 75, 1093-1098 (2010).

[26] A. T. Balaban, Clar formulas: How to draw and how not to draw formulas of polycyclic aromatic hydrocarbons, Polyc. Arom. Comp. 24. 83-89 (2004).

[27] I. Gutman, J. Đurđević, A. T. Balaban, A regularity for cyclic conjugation in acenaphthylene, fluoranthene, and their congeners, Polyc. Arom. Comp. 29, 3-11 (2009).

[28] I. Gutman, J. Đurđević, On $\pi$-electron conjugation in the five-membered ring of fluoranthenetype benzenoid hydrocarbons, J. Serb. Chem. Soc. 74, 765-771 (2009).

[29] J. Đurđević, I. Gutman, J. Terzić, A.T. Balaban, Cyclic conjugation in fluoranthene and its benzoderivatives. Part 1, catacondensed systems, $\mathrm{Po}_{\mathrm{O}}$ lyc. Arom. Comp. 29, 90-102 (2009).

[30] L. C. Sander, S. A. Wise, Polycyclic Aromatic Hydrocarbon Structure Index, NIST, Gaithersburg, 1997.

[31] S. Radenković, J. Đurđević, I. Gutman, Quantitative study of the PCP effect, Chem. Phys. Lett. 475, 289-292 (2009).

[32] I. Gutman, Theory of the PCP effect and related phenomena, J. Math. Chem. 47, 1309-1312 (2010).

[33] J. Đurđević, S. Radenković, I. Gutman, S. Marković, Testing the PCP-rule Monatsh. Chem. 140, 1305-1309 (2009).

[34] M. J. Frisch, G. W. Trucks, H. B. Schlegel, G. E. Scuseria, M. A. Robb, J. R. Cheeseman, J. A.
Montgomery Jr., T. Vreven, K. N. Kudin, J. C. Burant, J. M. Millam, S. S. Iyengar, J. Tomasi, V. Barone, B. Mennucci, M. Cossi, G. Scalmani, N. Rega, G.A. Petersson, H. Nakatsuji, M. Hada, M. Ehara, K. Toyota, R. Fukuda, J. Hasegawa, M. Ishida, T. Nakajima, Y. Honda, O. Kitao, H. Nakai, M. Klene, X. Li, J. E. Knox, H. P. Hratchian, J. B. Cross, V. Bakken, C. Adamo, J. Jaramillo, R. Gomperts, R. E. Stratmann, O. Yazyev, A. J. Austin, R. Cammi, C. Pomelli, J. W. Ochterski, P. Y. Ayala, K. Morokuma, G. A. Voth, P. Salvador, J. J. Dannenberg, V. G. Zakrzewski, S. Dapprich, A. D. Daniels, M. C. Strain, O. Farkas, D. K. Malick, A. D. Rabuck, K. Raghavachari, J. B. Foresman, J. V. Ortiz, Q. Cui, A. G. Baboul, S. Clifford, J. Cioslowski, B. B. Stefanov, G. Liu, A. Liashenko, P. Piskorz, I. Komaromi, R. L. Martin, D. J. Fox, T. Keith, M. A. Al-Laham, C. Y. Peng, A. Nanayakkara, M. Challacombe, P. M. W. Gill, B. Johnson, W. Chen, M. W. Wong, C. Gonzalez, J. A. Pople, (2003): Gaussian 03, Revision E.01-SMP. Gaussian Inc, Pittsburgh.

[35] K. B. Wiberg, Application of the Pople-SantrySegal CNDO method to the cyclopropylcarbinyl and cyclobutyl cation and to bicyclobutane, $\mathrm{Te}$ trahedron 24, 1083-1096 (1968).

[36] M. Giambiagi, M. S. Giambiagi, K. C. Mundim, Definition of a multicenter bond index, Struct. Chem. 1, 423-427 (1990).

[37] M. Giambiagi, M. S. de Giambiagi, C. D. dos Santos, A. P. de Figueiredo, Multicenter bond indices as a measure of aromaticity, Phys. Chem. Chem. Phys. 2, 3381-3392 (2000).

[38] J. Đurđević, I. Gutman, R. Ponec, Verifying the PCP-rule by five-center bond indices, J. Serb. Chem. Soc. 74, 549-554 (2009).

[39] R. B. Mallion, Topological ring-currents in condensed benzenoid hydrocarbons, Croat. Chem. Acta 81, 227-246 (2008).

[40] J. A. N. F. Gomes, R. B. Mallion, Aromaticity and ring currents, Chem. Rev. 101, 1349-1383 (2001).

[41] C. W. Haigh, R. B. Mallion, Proton magnetic resonance of planar condensed benzenoid hydrocarbons, Mol. Phys. 18, 767-772 (1970).

[42] A. T. Balaban, T. K. Dickens, I. Gutman, R. B. Mallion, Ring currents and the PCP rule, Croat. Chem. Acta 83, 209-215 (2010).

[43] P.v.R. Schleyer, C. Maerker, A. Dransfeld, H. 
Jiao, N.E. Hommes, Nucleus-independent chemical shifts: A simple and efficient aromaticity probe, J. Am. Chem. Soc. 118, 6317-6318 (1996).

[44] Z. Chen, C. S. Wannere, C. Corminboeuf, R. Puchta, P.v.R. Schleyer, Nucleus-independent chemical shifts (NICS) as an aromaticity criterion, Chem. Rev. 105, 3842-3888 (2005).

[45] A. Stanger, What is aromaticity: A critique of the concept of aromaticity - can it really be defined, Chem. Commun. 1939-1947 (2009).
[46] Gutman, J. Đurđević, B. Furtula, B. Milivojević, Cyclic conjugation in mono- and dicyclopenta-derivatives of anthracene and phenanthrene, Indian J. Chem. 47A, 803-807 (2008).

[47] A.T. Balaban, J. Đurđević, I. Gutman, Comments on $\pi$-electron conjugation in the five-membered ring of benzo-derivatives of corannulene, Polyc. Arom. Comp. 29, (2009) 185-205 (2009).

[48] I. Gutman, S. Jeremić, V. Petrović, Extending the PCP rule, Indian J. Chem. 48A, 658-662 (2009). 
